\title{
Outer-Selective Thin Film Composite (TFC) Hollow Fiber Membranes for Osmotic Power Generation
}

\author{
Ngoc Lieu Le ${ }^{1}$, N.M.S. Bettahalli ${ }^{1}$, S.P. Nunes ${ }^{1 *}$, Tai-Shung Chung ${ }^{1,2^{*}}$ \\ ${ }^{1}$ Biological and Environmental Science and Engineering Division \\ King Abdullah University of Science and Technology, Saudi Arabia 23955-6900 \\ ${ }^{2}$ Department of Chemical and Biomolecular Engineering, National University of Singapore, \\ 4 Engineering Drive 4, Singapore 117585, Singapore \\ *Corresponding authors: \\ Prof. Suzana Nunes \\ Email address: suzana.nunes@kaust.edu.sa
}

Tel.: +966544700052

Prof. Tai-Shung Chung

Email address: chencts@nus.edu.sg

Tel.: +65 65166645

Fax: +65 67791936 


\begin{abstract}
The pressure-retarded osmosis (PRO) process is a green technique for power generation to respond the world's need of energy sustainability. In this study, we have developed the vital component of the process, i.e. membrane, in the configuration of the outer-selective thin-film composite (TFC) hollow fiber, which is more practical than other configurations in the real applications. The support layer morphology and the formation of the selective polyamide layer have been optimized for a good PRO performance. The results show that the bore fluid with higher amount of the solvent N-methyl-2-pyrrolidone leads to full finger-like hollow fibers, which provide higher flux but lower pressure tolerance. The addition of higher amount of diethylene glycol into the dope solution, improves the pore formation and suppresses the macrovoid formation, while properly lowering the take-up speed increases their wall thickness and pressure tolerance. A simple alcohol-pre-wetting approach on the fiber support leads to a smooth and thin polyamide layer, which is favorable for a high water flux and power density. Its efficiency follows this order: n-propanol > ethanol > methanol > water. The n-propanol prewetted TFC membrane can tolerate 17 bar with a peak power density of $9.59 \mathrm{~W} / \mathrm{m}^{2}$ at room temperature, using $1 \mathrm{M} \mathrm{NaCl}$ solution as the draw solution and DI water as feed. This work demonstrates the potential of outer-selective TFC hollow fiber membranes for energy conversion via PRO process, provides useful database to fabricate suitable support morphology and raise a simple technique to practically form a thin and smooth polyamide layer.
\end{abstract}

Keywords: outer-selective, hollow fiber membrane, pressure-retarded osmosis, wetting 


\section{Introduction}

Energy is one of the imperative global issues because of the escalating demand but depleting supplies of fossil fuels [1]. Moreover, the negative environmental impacts of their combustion such as air and water pollution, and global warming emissions, have fostered scientists to explore numerous sustainable alternative energy resources [2]. Wind and solar power are two of the cleanest and most sustainable energy sources, as they produce no toxic pollution or global warming emissions. Both are well established and part of our all day life.

Recently, the renewable osmotic energy produced from the pressure-retarded osmosis (PRO) process has attracted great attention because of its huge energy potential (1750-2000 TWh/y) [3, 4], clean technique (zero carbon dioxide emission) [5-7] and high stability as compared to solar or wind [5]. This process harvests energy by exploiting the osmotic pressure gradient as a driving force across the membrane to induce water transport from the freshwater side towards the salty water side. The pressure built up within the salty water chamber can be released to spin an integrated turbine for electricity production [8].

One of the main barriers to commercialize the PRO process is the membrane because it is the heart of the entire process [9]. Thus, the vital challenge of an efficient osmotic power generation plant is the advancement of robust PRO membranes with (1) a strong and porous support to tolerate high-pressure operations with low internal concentration polarization, (2) high water flux and salt rejection to maximize power generation. To achieve these characteristics, thin film composite (TFC) membranes consisting of a porous support fabricated by phase inversion and a thin polyamide selective layer synthesized by interfacial polymerization, have been developed 
[10-17]. Common monomers used for interfacial polymerization are m-phenylene diamine and trimesoyl chloride.

PRO membranes have two configurations; namely, flat-sheet and hollow fiber. Flat-sheet PRO membranes were utilized by Statkraft to build the first osmotic power pilot in 2009 for concept demonstration [18]. For practical applications, the hollow fiber configuration has attracted great attention because it has high effective surface area per module volume, self-supporting capability without spacers, and easier module assembly. During the past decade, PRO TFC hollow fiber membranes have been developed in the manner where the thin selective layer is deposited on the lumen side of the fibers $[10,13-15,17]$.

Recently, PRO outer-selective hollow fiber membranes have attracted attention from both academics and industries because of their (1) less fiber blockage propensity and smaller pressure drop during actual PRO operations, (2) larger selective-layer area per module volume, (3) higher ease to control fouling with the selective layer on the outside of the fiber, and (4) less possible problems in the case of fiber collapse (outer selective-layer) than fiber bursting (inner selectivelayer) $[19,20]$. However, it is more challenging to develop the former than the latter because of two reasons. Firstly, although there are few studies on outer-selective PRO hollow fiber membranes, it is still not completely clear how to provide strong mechanical property and low internal concentration polarization by controlling the morphology. Table 1 summarizes the performance data of outer-selective PRO hollow fiber membranes in literature in comparison with the one in this study $[19,20]$. Secondly, it is more complicated to deposit a defect-free selective film on the outer surface than on the inner surface. In order to overcome this issue, Sun 
and Chung coated the fiber with the cushion layer of dopamine before the interfacial polymerization [20]. Because of strong adhesion and covalent links among dopamine, the polyimide support and the polyamide layer, the interaction between amine monomers and the support surface was improved and led to a more homogeneous and uniform polyamide layer. However, the instability of dopamine in the diamine solution made the process complicated.

Table 1. Pressure retarded osmosis (PRO) performance of outer-selective hollow fiber membranes in the literature.

\begin{tabular}{|c|c|c|c|c|}
\hline Membrane & $\begin{array}{l}\text { Selective layer } \\
\text { fabrication }\end{array}$ & Operation condition & $\begin{array}{l}\text { Power } \\
\text { density }\end{array}$ & Reference \\
\hline $\begin{array}{l}\text { PBI/POSS/PAN/PVP } \\
\text { Outer layer: PBI/POSS } \\
\text { Inner layer: PAN/PVP }\end{array}$ & $\begin{array}{l}\text { Dual-layer } \\
\text { hollow fiber }\end{array}$ & $\begin{array}{l}\text { Feed solution: } 10 \mathrm{mM} \mathrm{NaCl} \\
\text { Draw solution: } 1 \mathrm{M} \mathrm{NaCl} \\
\text { Applied pressure: } 15 \mathrm{bar}\end{array}$ & $5.10 \mathrm{~W} / \mathrm{m}^{2}$ & [19] \\
\hline TFC Matrimid® & $\begin{array}{l}\text { Interfacial } \\
\text { polymerization }\end{array}$ & $\begin{array}{l}\text { Feed solution: DI water } \\
\text { Draw solution: } 1 \mathrm{M} \mathrm{NaCl} \\
\text { Applied pressure: } 20 \mathrm{bar}\end{array}$ & $7.63 \mathrm{~W} / \mathrm{m}^{2}$ & {$[20]$} \\
\hline TFC Ultem ${ }^{\circledR}$ & $\begin{array}{l}\text { Interfacial } \\
\text { polymerization }\end{array}$ & $\begin{array}{l}\text { Feed solution: DI water } \\
\text { Draw solution: } 1 \mathrm{M} \mathrm{NaCl} \\
\text { Applied pressure: } 17 \text { bar }\end{array}$ & $9.59 \mathrm{~W} / \mathrm{m}^{2}$ & This study \\
\hline
\end{tabular}

PBI: polybenzimidazole; POSS: polyhedral oligomeric silsesquioxane; PAN: polyacrylonitrile; PVP: polyvinylpyrrolidone

This study aims to design outer-selective TFC hollow fiber membranes for PRO applications by (1) studying the effects of different hollow fiber supports spun from various conditions on transport properties; (2) exploring and optimizing the morphology and characteristics of hollow fiber supports for outer-selective TFC hollow fiber membranes; and (3) improving the polyamide layer with better water flux and PRO performance by pre-wetting the support with alcohols. Although alcohol pre-wetting improves membrane's wetting ability [21, 22], there is no in-depth science for the selection of suitable alcohols and how different alcohols affect the fiber substrate 
and subsequent formation of the polyamide layer. Polyetherimide Ultem ${ }^{\circledR}$ was employed as the support material in this work because it has an excellent mechanical property for high-pressure operations $[12,21,23]$. We believe this work may provide useful database for the fabrication of suitable support morphology for power generation via PRO process as well as the improvement of the polyamide layer for PRO membranes.

\section{Experimental}

\subsection{Hollow fiber support fabrication}

Ultem ${ }^{\circledR}$ hollow fiber supports were formed using a dry-jet wet spinning line via a non-solventinduced phase-inversion process as described elsewhere [24]. The detailed spinning conditions are listed in Table 2.

\subsection{Interfacial polymerization process and module preparation}

To fabricate TFC membranes, the aqueous phase was a m-phenylene diamine solution $(2 \mathrm{wt} \%$ in water) and the organic phase was a trimesoyl chloride solution $(0.15 \mathrm{v} / \mathrm{v} \%$ in $\mathrm{n}$-hexane $)$. The interfacial polymerization was carried one by one out on the outer surface of the Ultem ${ }^{\circledR}$ hollow fiber substrates. Prior to this process, one end of the fibers were sealed with epoxy, pre-wetted with alcohols in $20 \mathrm{~s}$ and then stabilized in DI water for $30 \mathrm{~min}$. The fibers were consequently dipped in the aqueous amine solution for $3 \mathrm{~min}$ at room temperature. After blotted with tissue papers to remove the excess liquid on the outer surface, the fibers were immersed into the trimesoyl chloride solution for 2 min to carry out interfacial polymerization. After that, the fibers were immersed in n-hexane for 2 min to wash away excess monomers. Then, the fiber ends with 
epoxy were cut and the fibers were then kept in a 25:75 (vol \%) glycerol/water solution overnight, and finally dried in air.

The membrane modules were fabricated by loading 2-3 fibers into a 3/8-inch tubing associated with two Swagelok® stainless steel male run tees at its ends. The effective length of the modules was around $13.4 \mathrm{~cm}$. Their ends were subsequently sealed with epoxy and cured at room temperature for $24 \mathrm{~h}$ before tests.

Table 2. Spinning conditions of Ultem ${ }^{\circledR}$ hollow fiber supports

\begin{tabular}{lllll}
\hline Spinning parameters & \multicolumn{4}{c}{ Fiber Code } \\
\cline { 2 - 5 } & HF-1 & HF-2 & HF-3 & HF-4 \\
\hline Dope solution (wt\%) & Ultem/DEG/ & Ultem/DEG/ & Ultem/DEG/ & Ultem/DEG/ \\
& NMP & NMP & NMP & NMP \\
& $17 / 13 / 70$ & $17 / 13 / 70$ & $17 / 11 / 72$ & $17 / 13 / 70$ \\
Bore fluid (wt\%) & NMP:water & NMP:water & NMP:water & NMP:water \\
& $(90: 10)$ & $(95: 5)$ & $(90: 10)$ & $(90: 10)$ \\
Dimensions of spinneret (mm) & $0.6: 0.9$ & $0.6: 0.9$ & $0.6: 0.9$ & $0.6: 0.9$ \\
External coagulant & Water & Water & Water & Water \\
Temperature $\left({ }^{\circ} \mathrm{C}\right)$ & Ambient & Ambient & Ambient & Ambient \\
Dope flow rate $(\mathrm{ml} / \mathrm{min})$ & 6 & 6 & 6 & 6 \\
Bore fluid flow rate $(\mathrm{ml} / \mathrm{min})$ & 3 & 3 & 3 & 3 \\
Air gap distance $(\mathrm{cm})$ & 1 & 1 & 1 & 1 \\
Take-up speed $(\mathrm{m} / \mathrm{min})$ & 36 & 36 & 36 & 30 \\
\hline
\end{tabular}

DEG: diethylene glycol; NMP: N-methyl-2-pyrrolidone

\subsection{Characterizations}

2.3.1. Microscopy 
The morphology of supports and TFC membranes was recorded using a field emission scanning electron microscope (FESEM, Quanta 200 or Nova Nano) and transmission electron microscopy (TEM, Tecnai Twin). Before FESEM observation, the hollow fibers were fractured in liquid nitrogen and then coated using a platinum/ iridium sputter coater. For TEM imaging, the hollow fibers were embedded in epoxy resin and cut with a glass knife on a Leica UC6 ultramicrotome at room temperature to give sections with a nominal thickness of $80 \mathrm{~nm}$.

\subsubsection{Positron annihilation spectroscopy (PAS)}

The free volume of the selective layer and the mean depth profiles of the TFC membranes were analyzed by doppler broadening energy spectroscopy using positron annihilation spectroscopy (PAS), combined with a slow positron beam. The system employed ${ }^{22} \mathrm{Na}$ isotope with the energy of $50 \mathrm{mCi}$ as a positron source. The hollow fiber samples were cut into a length of $2 \mathrm{~cm}$ and then aligned closely along the vertical direction on an aluminum plate. The fibers were packed alternatively into two layers to provide a seamless surface. A more detailed description of the setup can be found elsewhere [25]. The correlation of the mean implantation depth ( $\mathrm{Z}$ in $\mathrm{nm})$ and the incident positron energy ( $\mathrm{E}$ in $\mathrm{keV}$ ) was described by the following equation:

$$
\mathrm{Z}(\mathrm{E})=\frac{40}{\rho} \mathrm{E}^{1.6}
$$

Where $\rho$ is the density of the polymer material in $\mathrm{g} / \mathrm{cm}^{3}$. The parameters $\mathrm{S}$ was often used to characterize free volume of the polyamide layer and estimated from doppler broadening energy spectroscopy results as the ratio of the central part of the PAS spectrum to the total spectrum $[26,27]$.

\subsubsection{Collapse pressure}


Collapse pressure tests were carried out for the supports using a lab-scale PRO setup, where a high-pressure pump (Hydra-cell) was employed to recirculate DI water at the shell side of the fibers at $0.2 \mathrm{Lmin}^{-1}$. A peristaltic pump (Cole- Palmer) was used to flow DI water at $0.017 \mathrm{Lmin}^{-}$ ${ }^{1}$ into the lumen side of the fibers. The tests were performed at room temperature. The collapse pressure is defined as the pressure applied on the shell side at which the fiber was collapsed.

\subsubsection{Sorption tests}

The sorption tests of the supports in water and alcohols were carried out using the analogous flatsheet membranes fabricated from the similar dope solution of the hollow fibers. The pre-weighed flat-sheet films were immersed into sorption solutions, which were kept in a closed bottle at room temperature. The swollen films were then removed, absorbed with tissue paper to remove surface liquid and then weighed in a closed environment. The degree of sorption of the supports was determined by the equation:

$$
D S=\frac{W_{s}-W_{o}}{W_{o}}
$$

where $\mathrm{W}_{\mathrm{s}}$ and $\mathrm{W}_{\mathrm{o}}$ are the weights of the swollen and the dry films, respectively.

\subsubsection{Pore structural properties of hollow fiber supports}

Pore structural properties of hollow fiber supports, including pure water permeance, MWCO (molecular weight cut-off), pore size, and pore size distribution were determined by using a labscale circulating filtration unit as previously described [28]. Since the selective layer is deposited on the outer surface of the fibers, the feed solutions were provided from the outside, while the permeate were achieved from their inside. The pure water permeance PWP $\left(\mathrm{Lm}^{-2} \mathrm{bar}^{-1} \mathrm{~h}^{-1}\right)$ was 
measured by circulating water into the module at a flow rate of $0.2 \mathrm{Lmin}^{-1}$ under 1 bar and then calculated using the equation:

$$
P W P=\frac{Q}{\Delta P \times A_{m}}
$$

where $\mathrm{Q}$ is the water permeation volumetric flow rate $(\mathrm{L} / \mathrm{h}), \mathrm{A}_{\mathrm{m}}$ is the effective area $\left(\mathrm{m}^{2}\right)$, and $\Delta \mathrm{P}$ is the transmembrane pressure drop (bar).

Pore size, pore size distribution, and MWCO of hollow fibers were estimated via solute separation experiments with $200 \mathrm{mg} / \mathrm{L}$ neutral organic solutes (polyethyleglycol with different molecular weights) by circulating the feed solutions through the modules at 1 bar. The system was stabilized for $1 \mathrm{~h}$ before both collecting the feed and permeate. Concentrations of feed and permeate were analyzed using a Shimazu total organic carbon analyzer. The solute rejection $R_{T}$ (\%) was determined using the equation:

$$
R_{T}(\%)=\left(1-\frac{c_{p}}{c_{f}}\right)
$$

where $c_{p}$ and $c_{f}$ are the solute concentrations in the permeate and feed solutions, respectively. The experiments were repeated 3 times and average values was recorded. From the relationship between $\mathrm{R}_{\mathrm{T}}(\%)$ and solute molecular weight, pore size, pore size distribution, and MWCO can be calculated as previously described [28].

\subsection{Reverse osmosis evaluation of the TFC membranes}

Each TFC membrane was tested for its pure water permeance, $A\left(\mathrm{Lm}^{-2} \mathrm{bar}^{-1} \mathrm{~h}^{-1}\right)$ in the similar method and equation for those of the supports. The feed of $200 \mathrm{mg} / \mathrm{L} \mathrm{NaCl}$ at $0.2 \mathrm{Lmin}^{-1}$ and 1 bar was employed to calculate the salt rejection using eq. 4. Accordingly, the salt permeance B can be determined based on the equation: 


$$
\frac{1-R_{T}}{R_{T}}=\frac{1}{(\Delta P-\Delta \pi)} B
$$

where $\Delta \mathrm{P}$ is the hydraulic pressure across the membrane while $\Delta \pi$ is the osmotic pressure difference between the feed and permeate.

\subsection{Forward osmosis (FO) performance}

FO tests were performed using a lab-scale FO setup at room temperature. The draw solution of 1 $\mathrm{M} \mathrm{NaCl}$ and the feed solution of DI water were recirculated counter-currently into the shell side

and lumen side with the flow rates of 0.2 and $0.017 \mathrm{Lmin}^{-1}$, respectively. The water permeation flux, $\left(\mathrm{J}_{\mathrm{w}}, \mathrm{Lm}^{-2} \mathrm{~h}^{-1}\right)$ was calculated from the following equation:

$$
J_{w}=\frac{\Delta v}{A_{m} t}
$$

where $\Delta \mathrm{v}$ is the volume change of the feed solution over a predetermined time $\mathrm{t}(\mathrm{h})$ and $\mathrm{A}_{\mathrm{m}}\left(\mathrm{m}^{2}\right)$

is the effective membrane area. The salt reverse flux, $\mathrm{J}_{\mathrm{s}}$, in $\mathrm{gm}^{-2} \mathrm{~h}^{-1}$, was calculated from the following equation:

$$
J_{s}=\frac{\left(c_{t} v_{t}-c_{o} v_{o}\right)}{A_{m} t}
$$

where $c_{o}$ and $v_{o}$ are the salt concentration and volume of the initial feed; and $c_{t}$ and $v_{t}$ are the salt concentration and volume of the final feed, respectively. The reported data were the average values of 3-time repeated experiments.

\subsection{PRO performance}

PRO tests were carried out with a lab-scale PRO setup, which were similar to that used for collapse pressure tests. However, the shell side of the membranes was recirculated by the draw solution $(1 \mathrm{M} \mathrm{NaCl})$. The power density is calculated by the following equation: 


$$
W=J_{w} \Delta P
$$

where $\Delta \mathrm{P}$ is the hydraulic pressure difference across the membrane and $\mathrm{J}_{\mathrm{w}}$ is the water permeation flux.

\section{Results and Discussion}

\subsection{Ultem $®$ hollow fiber support characteristics}

In order to explore the suitable morphology of hollow fiber supports for the development of outer-selective TFC membranes, various spinning parameters have been investigated as listed in Table 2. Among them, HF-1 is a control hollow fiber support while HF-2, HF-3 and HF-4 were spun from dopes with different bore fluid compositions, dope formulas and take-up speeds.

Figures 1 compares the FESEM images of HF-1 and HF-2. HF-2 has a full finger-like structure where macrovoids start from the inner surface to near the outer surface, while HF-1 has a mixed sponge- and finger-like structure. As a result, HF-2 has an inhomogeneous inner surface consisting of large pores with sizes matching the tip of finger-like macrovoids. These pores play as transport channels for permeate across the hollow fibers and reduce internal concentration polarization. In contrast, the inner surface of HF-1 has a fully cellular structure, which may provide mechanical support during high pressure operations. In addition, the outer surface of HF2 is less smooth and has more pinholes than that of HF-1 due to the delayed demixing at the inner surface using a higher NMP concentration as the bore fluid [29-31]. As displayed in Table 3 , both hollow fiber supports have surface pore sizes smaller than $<50 \mathrm{~nm}$ and relatively narrow pore size distributions with a mean pore diameter $\left(\mu_{\mathrm{p}}\right)<15 \mathrm{~nm}$ and a geometric standard deviation $\left(\sigma_{\mathrm{p}}\right)$ of about 1.65 . 


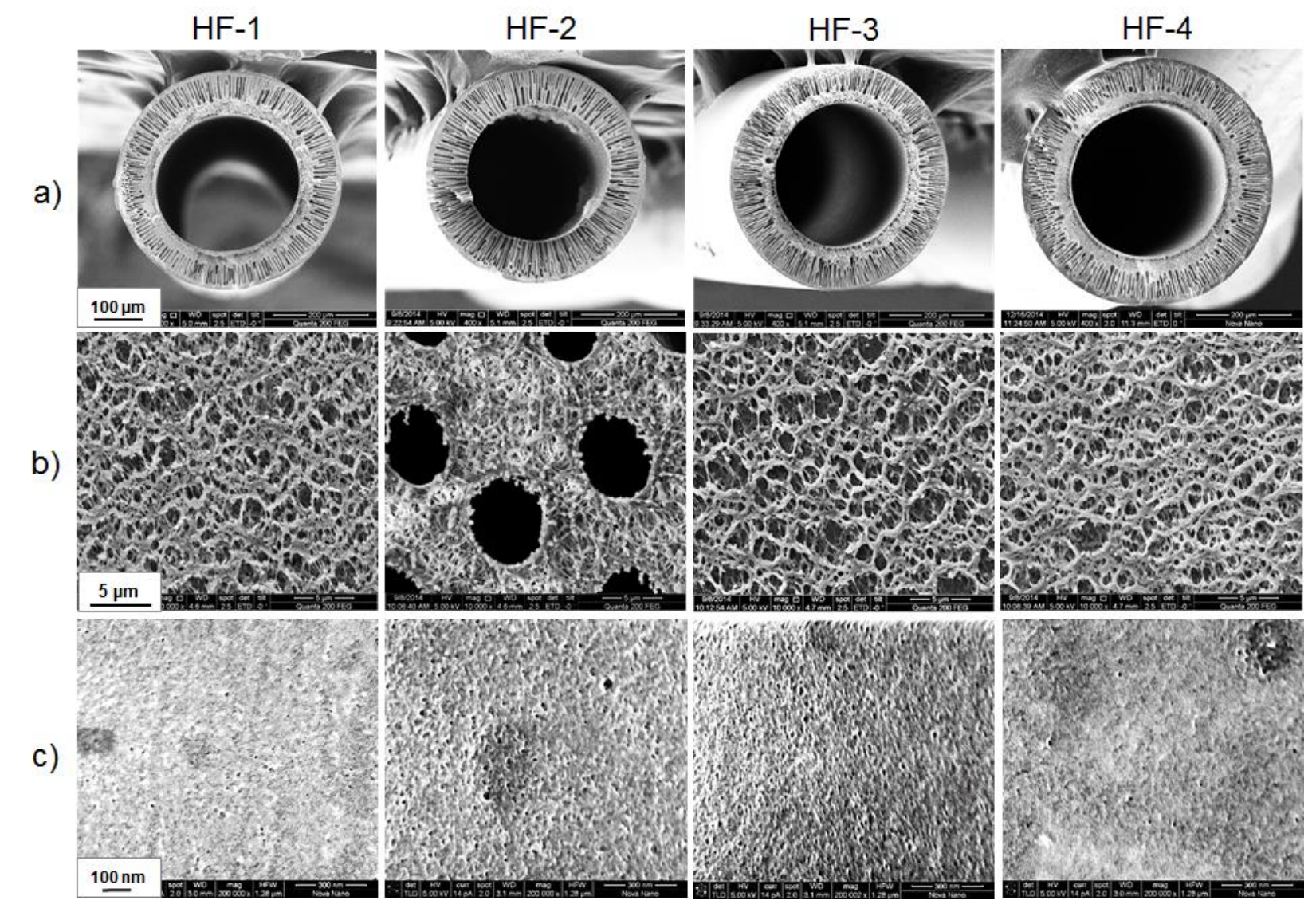

Figure 1. Morphology of the hollow fiber supports used for fabricating the outer-selective PRO membranes: (a) cross-section, (b) inner surface, and (c) outer surface

Table 3 shows that both HF-1 and HF-2 have high pure water permeance (PWP) of 524 and 952 $\mathrm{Lm}^{-2} \mathrm{~h}^{-1} / \mathrm{bar}$, respectively, while their corresponding collapse pressures are 15 and 11 bar. Since the substrate morphology determines the transport and mechanical properties of the resultant TFC membranes [13-17], these results indicate a trade-off existing between the PWP value of the substrates and the operation pressure of the resultant PRO membranes. A support comprising a full finger-like structure with a higher PWP may result in a PRO TFC membrane with a lower 
collapse pressure than that made from a support consisting of a mixed sponge- and finger-like structure.

Table 3. Outer diameter, mean pore size, standard deviation, molecular weight cut-off (MWCO), collapse pressure and pure water permeance (PWP) of Ultem ${ }^{\circledR}$ hollow fiber supports

\begin{tabular}{cccccccc}
\hline Support & $\begin{array}{c}\text { Outer } \\
\text { diameter } \\
(\mu \mathrm{m})\end{array}$ & $\begin{array}{c}\text { Wall } \\
\text { thickness } \\
(\mathrm{nm})\end{array}$ & $\begin{array}{c}\mu_{\mathrm{p}} \\
(\mathrm{nm})\end{array}$ & $\sigma_{\mathrm{p}}$ & $\begin{array}{c}\text { MWCO } \\
(\mathrm{kDa})\end{array}$ & $\begin{array}{c}\mathrm{PWP} \\
\left(\mathrm{Lm}^{-2} \mathrm{bar}^{-1} \mathrm{~h}^{-1}\right)\end{array}$ & $\begin{array}{c}\text { Collapse } \\
\text { pressure } \\
(\text { bar })\end{array}$ \\
\hline HF-1 & 468 & 87 & 8.0 & 1.64 & 52.6 & 524 & 15 \\
$\mathrm{HF}-2$ & 458 & 87 & 11.5 & 1.66 & 104.0 & 952 & 11 \\
$\mathrm{HF}-3$ & 468 & 87 & 5.9 & 1.77 & 35.9 & 131 & 18 \\
$\mathrm{HF}-4$ & 527 & 103 & 5.1 & 1.88 & 31.1 & 270 & 17 \\
\hline
\end{tabular}

In order to tailor the support towards high pressure tolerance for PRO applications, dope formula and take-up speed were further modified. A comparison between HF-1 and HF-3 in Figure 1 shows that they have similar morphology, outer diameters, inner and outer surface structures. However, a higher magnification in Figure 2 indicates that HF-3 has more and thinner finger-like macrovoids because of a smaller amount of diethylene glycol (DEG) in its dope formula. The addition of ethylene glycol, diethylene glycol, polyethylene glycol or glycerol has been reported to improve pore formation, suppress macrovoid formation and transfer the membrane morphology from the finger-like to sponge-like structure [32-34]. As a result, HF-3 spun from a smaller amount of DEG in its dope has a higher number of finger-like macrovoids with finer macrovoid channels. Additionally, compared to HF-1, HF-4 has a similar morphology but a larger outer diameter of $527 \mathrm{~nm}$ and a thicker fiber wall of $97 \mathrm{~nm}$, due to a smaller elongational stress applied on the nascent fiber because of using a lower take-up speed [35-38]. These morphological changes render HF-3 and HF-4 to be mechanically stronger with higher collapse 
pressures of 18 and 17 bar, respectively (Table 3). Table 3 shows that the PWP values of HF-3 and HF-4 drop to 131 and $270 \mathrm{Lm}^{-2} \mathrm{~h}^{-1} / \mathrm{bar}$, respectively, while their mean pore diameters $\left(\mu_{\mathrm{p}}\right)$ decrease to about $5.5 \mathrm{~nm}$ with geometric standard deviations $\left(\sigma_{\mathrm{p}}\right)$ of about 1.80 because of less porous top surface and overall structure. Compared to HF-1 and HF-2, HF-3 and HF-4 have better surfaces for interfacial polymerization because of smaller mean pore diameters [39-41].
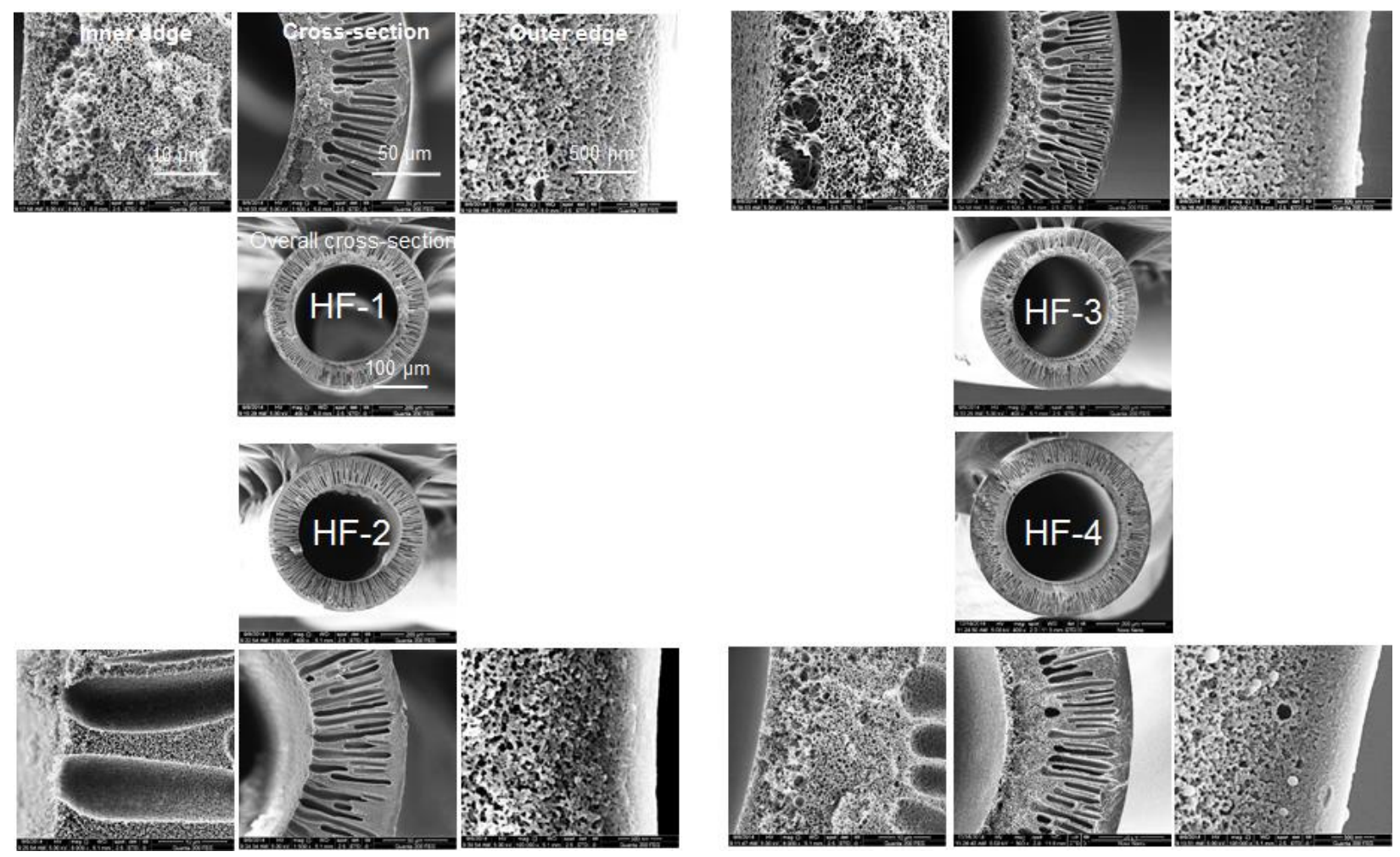

Figure 2. Detailed morphology of hollow fiber supports for preparing the outer-selective PRO membranes

\subsection{Outer selective TFC hollow fiber membranes}

Figure 3 shows the FESEM surface images of PRO TFC membranes after conducting interfacial polymerization on the ethanol-pre-wetted hollow fiber supports. A thin polyamide layer with rough ridge-valley morphology was observed. Among these four hollow fibers, HF-1, HF-3 and 
HF-4 have a smooth and homogeneous polyamide layer with a thickness of about $210 \mathrm{~nm}$, while HF-2 has a rougher and thicker polyamide layer with a thickness of about $245 \mathrm{~nm}$. However, the water permeance for HF-2 is the highest among these hollow fibers. The polyamide layer morphology was then investigated in more details by TEM and the free volume was estimated by PAS. The TEM images are shown as insets in Figure 3. They confirm that the polyamide layer of the HF-2 TFC membrane is rougher than that of the HF-4 TFC membrane and their thicknesses are consistent with those estimated from FESEM images.

a)

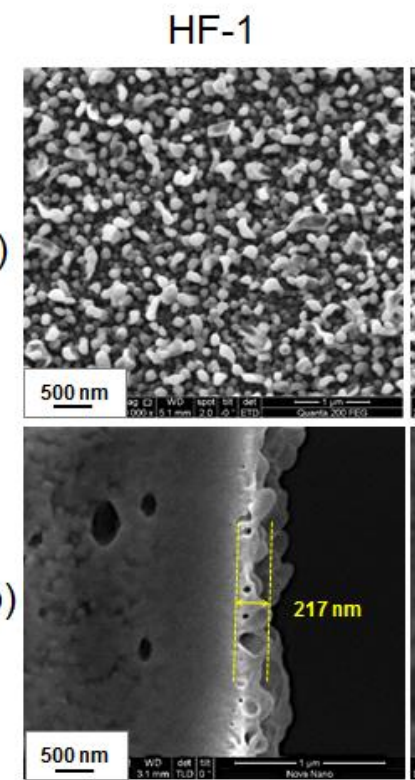

HF-2

$\mathrm{HF}-3$

HF-4
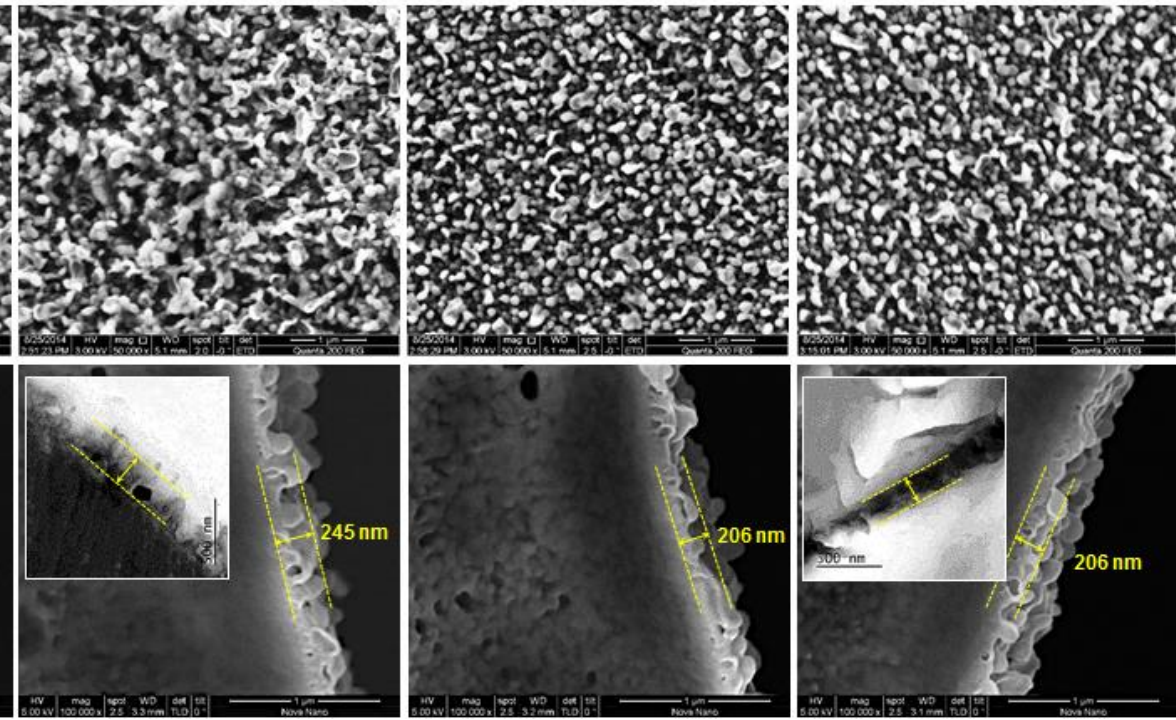

Figure 3. (a) Outer surface and (b) outer edge morphology of outer-selective TFC hollow fiber membranes prepared from different supports (FESEM images; insets are TEM images)

To compare the free volume and detailed structure of the polyamide layers formed on different supports, PAS experiments, coupled with a monoenergetic slow positron beam, were performed. Fig. 4 shows the $\mathrm{S}$ parameter versus positron incident energy (or mean depth) for the TFC membranes, the patterns of which are consistent with previous studies for the TFC membranes made of other support materials $[27,42]$. It's worth to note that this S parameter here is totally 
different from another commonly used S parameter (structural parameter), which is related to the effective diffusion length of the membrane. The $\mathrm{S}$ parameter of doppler broadening energy spectroscopy is the ratio of the central part of the PAS spectrum to the total and directly related to free volume in the membrane. The peak-like regions in the positron incident energy from 0.7 $\mathrm{keV}$ to $2.0 \mathrm{keV}$ and from $7.0 \mathrm{keV}$ to $12 \mathrm{keV}$ correspond to the polyamide layer and the dense skin of the Ultem ${ }^{\circledR}$ support, respectively. The $S$ parameter is the highest for the polyamide layer of the TFC HF-2 membrane, which indicates that its free volume is the highest. The largest free volume justifies the highest water permeance and the lowest $\mathrm{NaCl}$ rejection of $46.2 \%$ (a corresponding salt permeance B of $5.3 \mathrm{Lm}^{-2} \mathrm{~h}^{-1}$ ) observed for this TFC HF-2 membrane under the $\mathrm{RO}$ mode, as shown in Figure 5a. The $\mathrm{S}$ parameters of the polyamide layers are nearly similar for other 3 TFC membranes.
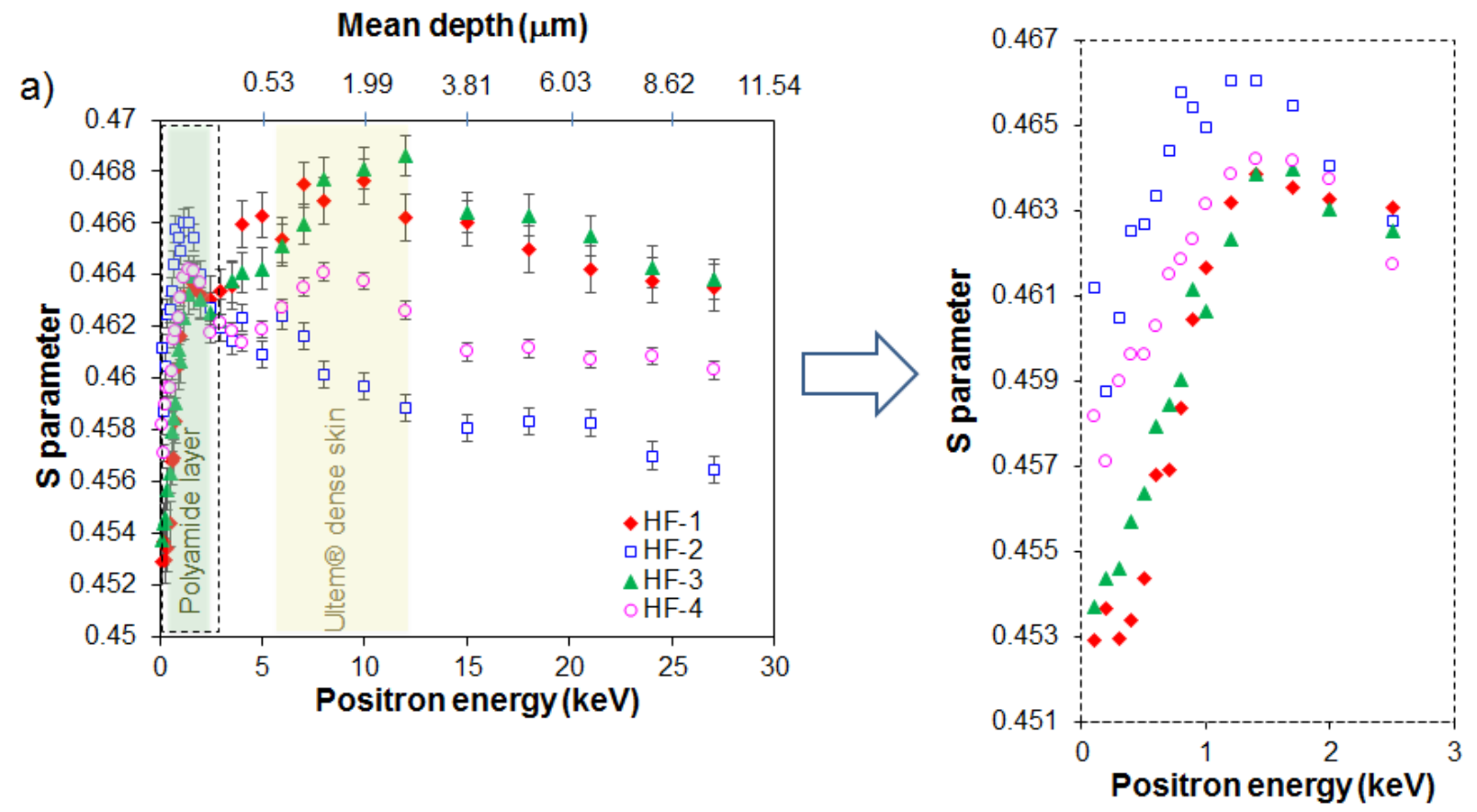

Figure 4. S parameter (ratio of the central part of the PAS spectrum to the total) as a function of position incident energy of TFC hollow fiber membranes prepared from different supports 
For other 3 TFC membranes, their PWP values under the RO mode are in the order of HF-1 > HF-4 > HF-3 which follows exactly the PWP order of their supports. Because their polyamide layers have a similar structure and thickness, the PWP order of these TFC membranes is mainly governed by the supports. FO experiments were also carried out using a cross-flow system under the PRO mode. As shown in Figure 5b, the water flux follows the PWP order of HF-2 > HF-1 > $\mathrm{HF}-4>\mathrm{HF}-3$ in the range of 17.4 to $50.3 \mathrm{Lm}^{-2} \mathrm{~h}^{-1}$.

a)

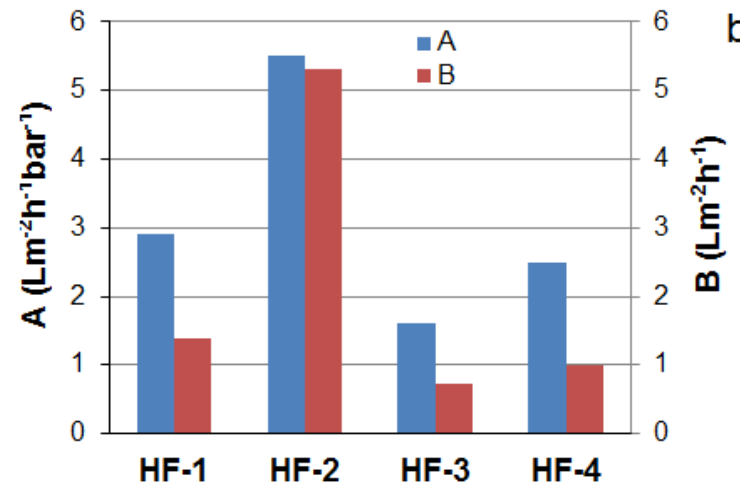

b)

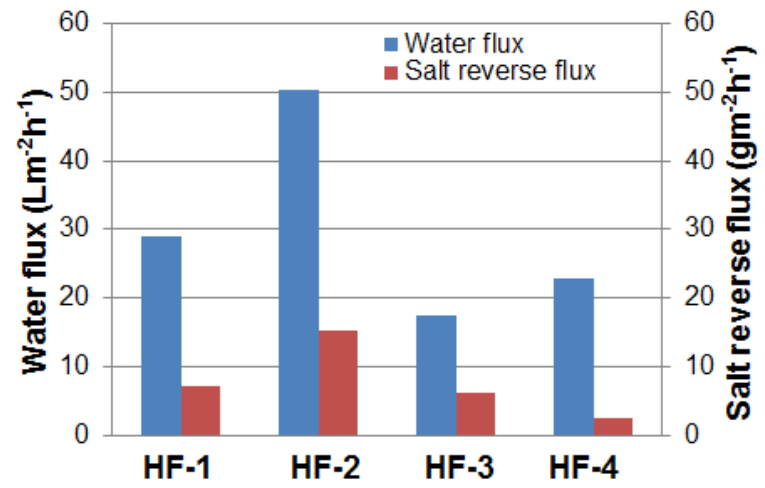

Figure 5. (a) Water permeance (A) and salt permeance (B) of outer-selective TFC hollow fiber membranes, and (b) Water flux and salt reverse flux of outer-selective TFC hollow fiber membranes.

The TFC membranes were further evaluated by high-pressure PRO experiments. As shown in Figure 6, even though the initial water flux of the TFC HF-2 membrane is very high, it drops rapidly under high pressures and nearly has a similar value with those of TFC HF-1 and HF-4 membranes at the applied pressure of 11 bar. The quick flux decrease of the TFC HF-2 membrane is due to two reasons. Firstly, its high salt permeance not only reduces the effective 
osmotic driving force across the membrane but also induces server internal concentration polarization. Secondly, since its polyamide layer was formed on large-sized pores (Figure 1), it may be deformed under high pressures and become defective with worsen internal concentration polarization and flux. In contrast, the other three TFC membranes exhibit a similar fluxdecreasing pattern with applied pressure.
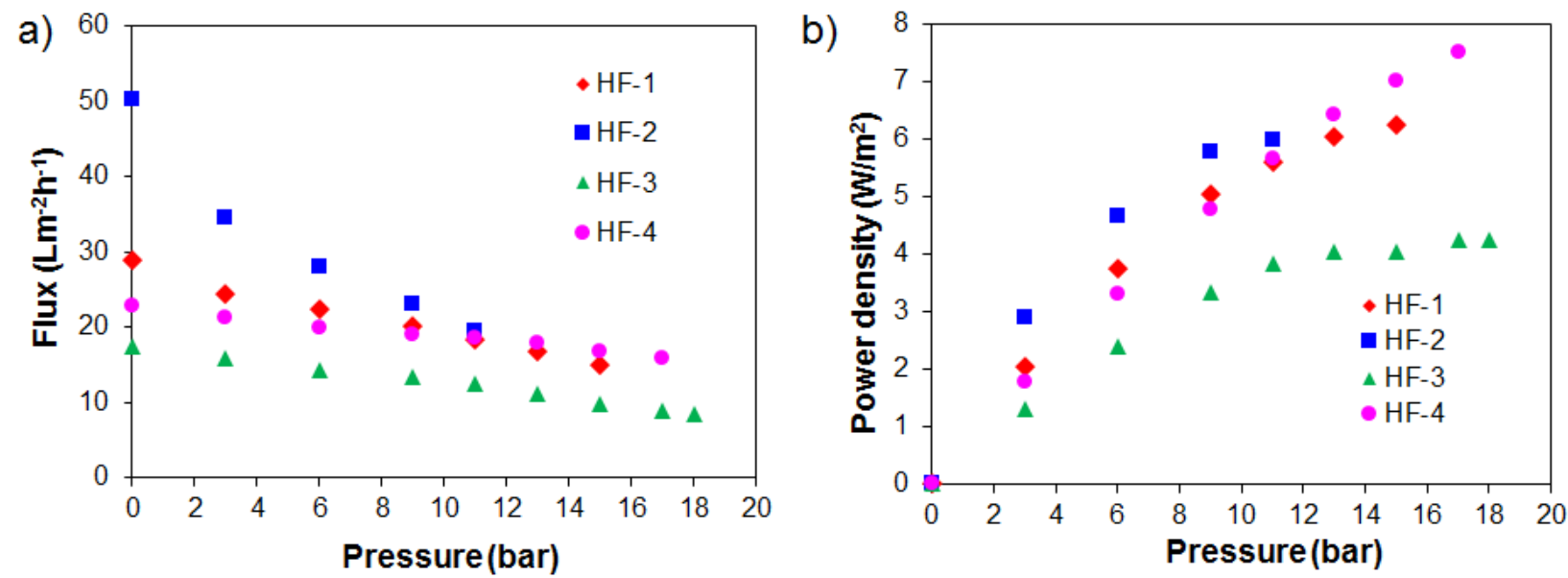

Figure 6. PRO performance of outer-selective TFC hollow fiber membranes: (a) water flux and (b) power density as a function of pressure

As implied from eq. 8, the power density is a product of pressure difference and flux obtained at that pressure. Figure 6 shows that the TFC HF-2 membrane has a high initial water flux but a low peak power density of $5.96 \mathrm{~W} / \mathrm{m}^{2}$ because of the rapid flux decline with pressure and low collapse pressure. The TFC HF-3 membrane has the lowest power density of $4.25 \mathrm{~W} / \mathrm{m}^{2}$ due to its smallest initial flux of $17.4 \mathrm{Lm}^{-2} \mathrm{~h}^{-1}$. Among the four TFC membranes, the TFC HF-4 membrane has the highest peak power density of $7.51 \mathrm{~W} / \mathrm{m}^{2}$ because of its combination of high pressure tolerance, reasonably high initial flux and low internal concentration polarization. In conclusion, a desirable support (HF-4) for PRO membranes should have a mixed finger-like and 
sponge-like structure (rather than the full finger-like structure of HF-2) and adequately large wall thickness (as compared with that of HF-1) to provide strong mechanical strength while it should have wider finger-like macrovoids (as compared to thinner ones of HF-3) to provide low transport resistance. These properties can be achieved by lowering the solvent amount in the bore fluid, decreasing the take-up speed and adding more amount of diethylene glycol into the dope solution, respectively. Further optimizations on other spinning conditions such as air gap, coagulant formation or temperature might be efficient to improve the performance to a higher extent. Since the HF-4 support has resulted in the best PRO TFC membrane, it was chosen for further investigation.

\subsection{Enhancing PRO performance through alcohol pre-wetting on the support}

In order to improve PRO performance, three types of alcohol pre-wetting were conducted on hollow fiber substrates before interfacial polymerization. Table 4 summarizes the physicochemical properties of these three alcohols, water and n-hexane as well as the substrate material Ultem ${ }^{\circledR}$ [43-51]. Figure 7 shows FESEM images of the polyamide layer formed on the HF-4 supports pre-wetted by water and different alcohols. The polyamide layer formed on the water-pre-wetted support has a rough ridge-valley surface with a large thickness of $238 \mathrm{~nm}$. When the supports are pre-wetted by alcohols, the polyamide layers become thinner with smaller nodules and smoother surfaces. The insets in Figure 7 show their TEM images and confirm that the water-pre-wetted TFC membrane has a rougher polyamide layer than those of alcohol-prewetted TFC membranes. Because of the greater darkness, the TEM images also indicate that the polyamide layer of the alcohol-pre-wetted TFC membranes has a higher density, which is consistent with PAS observation. As shown in Figure 8, the $\mathrm{S}$ parameter curve is higher for the 
polyamide layer of the water-pre-wetted TFC membrane than those of alcohol-pre-wetted TFC membranes, which indicates the former has a higher free volume or less dense structure than the latter.

Table 4. Physicochemical properties of Ultem ${ }^{\circledR}$, water, methanol, ethanol, n-propanol and nhexane

\begin{tabular}{|c|c|c|c|c|c|}
\hline $\begin{array}{l}\text { Solvent/ } \\
\text { polymer }\end{array}$ & $\begin{array}{l}\text { Molecular } \\
\text { weight } \\
(\mathrm{g} / \mathrm{mol})\end{array}$ & $\begin{array}{l}\text { Density } \\
\left(\mathrm{g} / \mathrm{cm}^{3}\right) \\
\text { at } 20^{\circ} \mathrm{C} \\
{[50]}\end{array}$ & $\begin{array}{l}\text { Viscosity } \\
\times 10^{3} \\
(\mathrm{~Pa} . \mathrm{s}) \\
{[51]}\end{array}$ & $\begin{array}{l}\text { Solubility } \\
\text { parameter } \\
\left(\mathrm{MPa}^{1 / 2}\right) \\
{[44]}\end{array}$ & $\begin{array}{l}\text { Surface } \\
\text { tension } \\
\text { at } 20^{\circ} \mathrm{C} \\
(\mathrm{mN} / \mathrm{m}) \\
{[52,53]}\end{array}$ \\
\hline Water & 18.02 & 0.998 & 0.890 & 47.9 & 72.8 \\
\hline $\begin{array}{l}\text { Methanol } \\
5 \mathrm{wt} \% \\
\text { Methanol/Water }\end{array}$ & 32.04 & 0.793 & 0.547 & 29.6 & $\begin{array}{l}22.7 \\
63.5\end{array}$ \\
\hline $\begin{array}{l}\text { Ethanol } \\
5 \mathrm{wt} \% \\
\text { Ethanol/Water }\end{array}$ & 46.07 & 0.790 & 1.140 & 26.5 & $\begin{array}{l}22.1 \\
56.4\end{array}$ \\
\hline $\begin{array}{l}\text { n-Propanol } \\
5 \mathrm{wt} \% \\
\text { Propanol/Water }\end{array}$ & 60.10 & 0.804 & $\begin{array}{l}1.950 \\
{[45]}\end{array}$ & 24.5 & $\begin{array}{l}23.7 \\
42.5\end{array}$ \\
\hline n-Hexane & 86.18 & $\begin{array}{l}0.655 \\
{[43]}\end{array}$ & $\begin{array}{l}0.298 \\
{[43]}\end{array}$ & 30.4 [49] & 18.4 \\
\hline Ultem® 1000 & 39000 & 1.27 [47] & N.A & $23.7[46]$ & \\
\hline
\end{tabular}




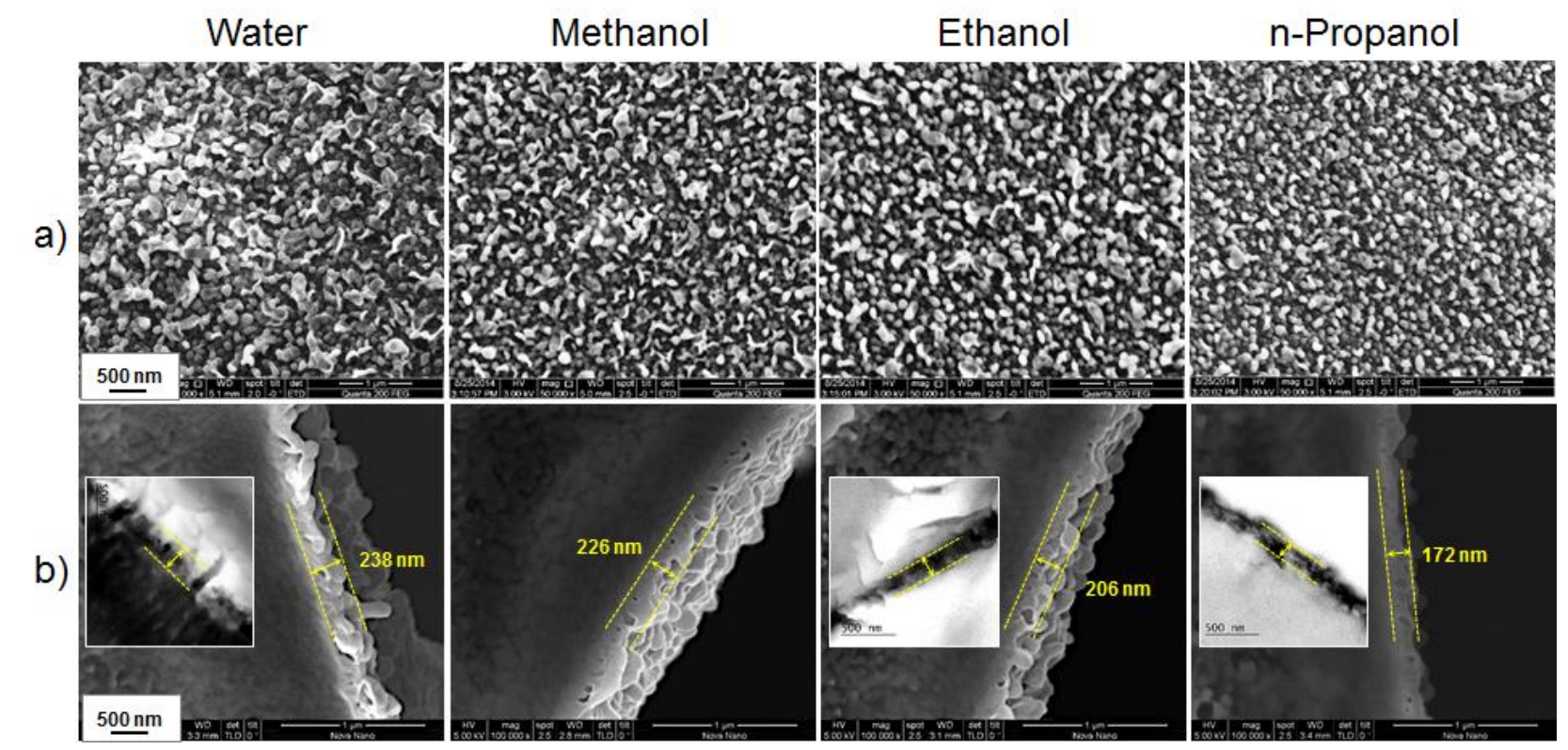

Figure 7. (a) Outer surface and (b) outer-edge morphology of outer-selective TFC hollow fiber membranes prepared from the HF-4 supports pre-wetted with water, methanol, ethanol and npropanol (FESEM images; insets are TEM images)

The benefits of pre-wetting the support with alcohols can be understood from two aspects. Firstly, compared to water, alcohols have lower surface energy and closer solubility parameters with Ultem ${ }^{\circledR}$. As a result, alcohol pre-wetting facilitates substrate pores more accessible to the aqueous solution and the m-phenylene diamine monomer would be more uniformly distributed inside the support, leading to form a more homogeneous and thinner polyamide layer [39]. Secondly, alcohols may slightly swell up the substrate and reduce its pore sizes. As a consequence, the transport of m-phenylene diamine toward trimesoyl chloride during interfacial polymerization is less turbulent (i.e. less diffusive backward into pores of the support) and results in a smoother polyamide layer [40]. 
Figure $7 \mathrm{~b}$ also shows that the polyamide thickness is in the order of water $>$ methanol $>$ ethanol $>$ n-propanol, which is in agreement with the trend of their S parameters (i.e., free volume) as displayed in Figure 8. Since the solubility parameter is in the order of water > methanol > ethanol > n-propanol $\approx$ Ultem ${ }^{\circledR}$, n-propanol has the best interaction with the Ultem ${ }^{\circledR}$ hollow fiber. This explains why n-propanol pre-wetting produces the thinnest and smoothest polyamide layer. To prove the interaction between Ultem ${ }^{\circledR}$ and water or alcohols, sorption tests were carried out using Ultem ${ }^{\circledR}$ flat-sheet substrates. As shown in Figure 9a, the sorption data absolutely follow the prediction from their solubility parameters. In addition, the sorption amount of n-propanol after 17 days is almost equal to that after 7 days while those of methanol and ethanol sorption increase 20 and $24 \%$, respectively. This implies that Ultem ${ }^{\circledR}$ absorbs npropanol faster than methanol and ethanol which make its equilibrium reach in a shorter time. 


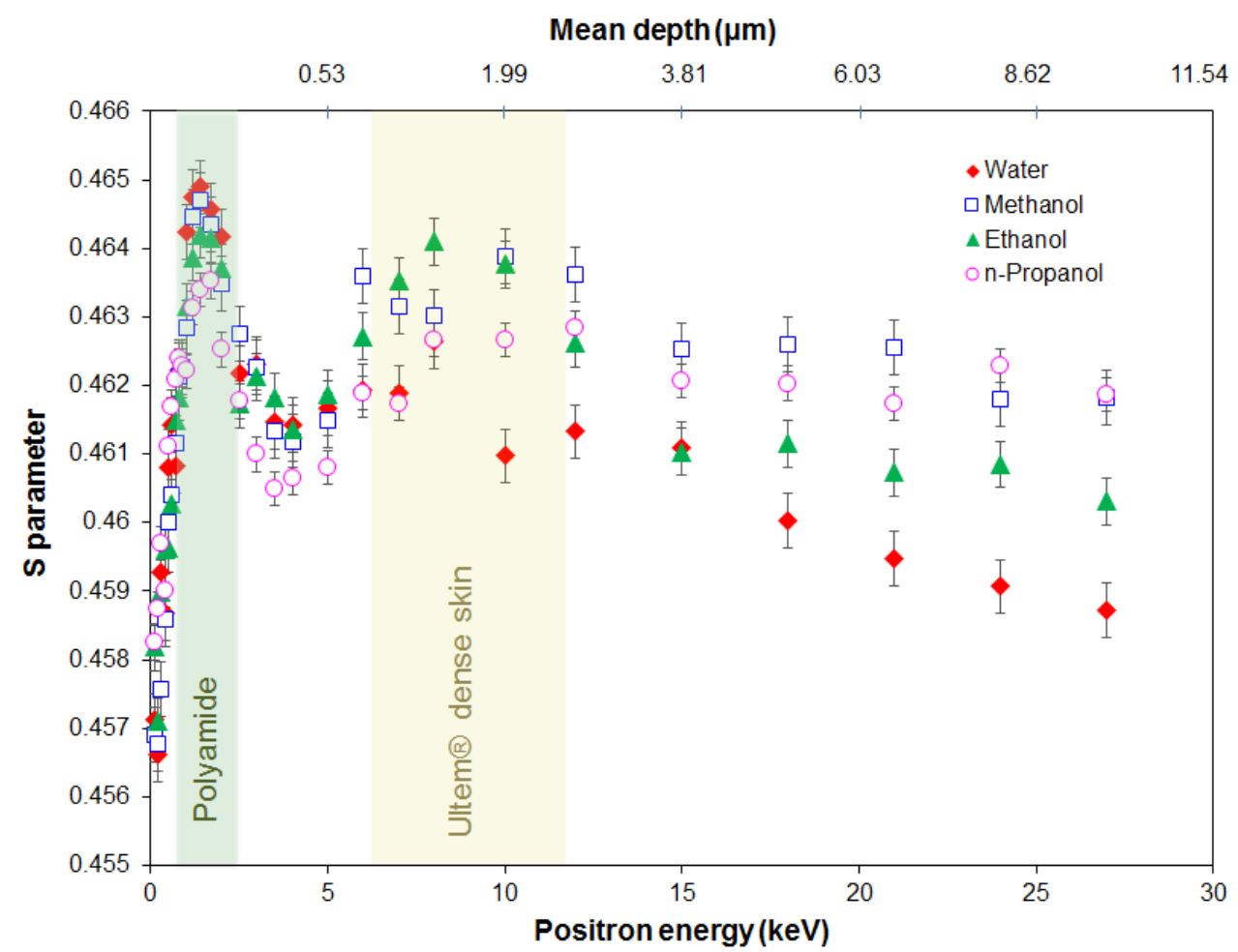

Figure 8. S (ratio of the central part of the PAS spectrum to the total) parameter as a function of position incident energy of TFC hollow fiber membranes prepared from the HF-4 supports prewetted with water and alcohols 
a)

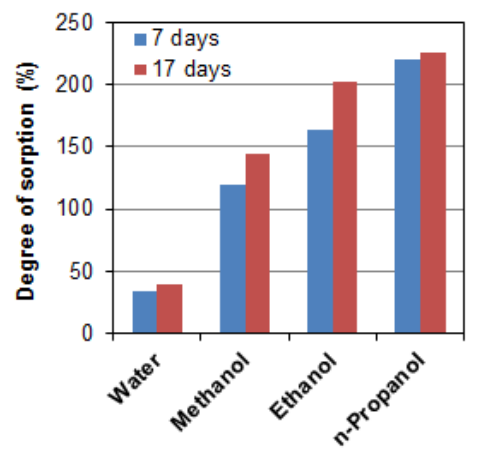

b)

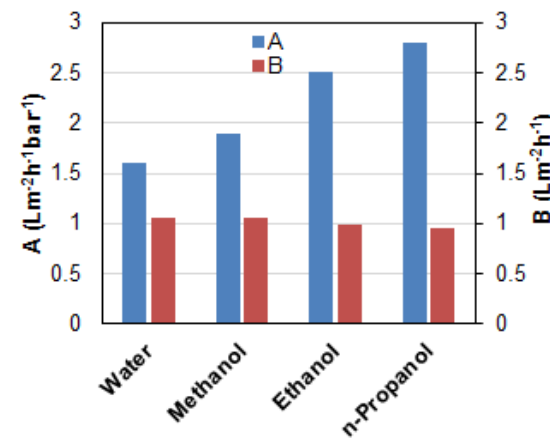

c)

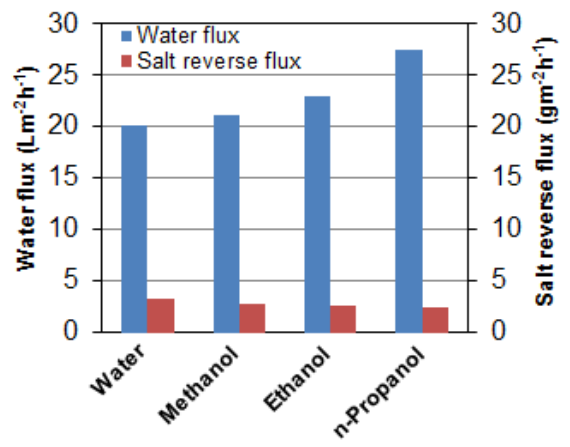

Figure 9. (a) Degree of sorption of the HF-4 fiber analogous flat-sheet supports in different solvents at room temperature; (b) Water permeance (A) and salt permeance (B); and (c) Water flux and salt reverse flux of outer-selective TFC hollow fiber membranes prepared from the HF4 supports pretreated with different solvents

Figures $9 \mathrm{~b}$ and 9c compare A, B parameters and FO performance of these TFC membranes. Consistent with SEM, TEM and PAS data, the water flux and water permeance (A) increase while the salt reverse flux and salt permeance (B) slightly decrease in the order of pre-wetting agents of water, methanol, ethanol and n-propanol. Since the n-propanol-pre-wetted TFC membrane displays the best FO performance, it was tested under PRO for power generation. As illustrated in Figure 10, its flux decreases $26 \%$ to $20.3 \mathrm{Lm}^{-2} \mathrm{~h}^{-1}$ at the maximal pressure tolerance of 17 bar. The obtained peak power density is $9.59 \mathrm{~W} / \mathrm{m}^{2}$. It's worth to note that the fibers do not collapse at this pressure and hence the performance would be even higher. As shown in Table 1, this performance surpasses other outer-selective PRO TFC hollow fibers made of Matrimid® $\left(5.10 \mathrm{~W} / \mathrm{m}^{2}\right)$ and polybenzimidazole hollow fibers made from phase inversion $\left(7.63 \mathrm{~W} / \mathrm{m}^{2}\right)[19$, 20] at almost similar operation conditions. Its better performance is attributed to its stronger 
support (higher collapse pressure than that of polybenzimidazole hollow fibers) and higher water flux due to its smoother and thinner selective layer. Since Ultem ${ }^{\circledR}$ is cheaper than Matrimid ${ }^{\circledR}$ and PBI, it may have greater potential for commercialization. Further works will focus on fouling studies and long-term stability.

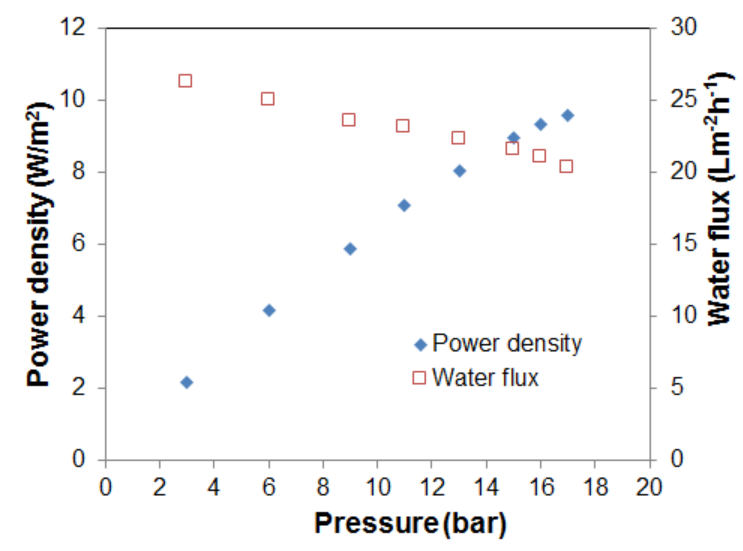

Figure 10. PRO performance of the outer-selective TFC hollow fiber membranes prepared from n-propanol pre-wetted HF-4 support: water flux and power density as a function of pressure

\section{Conclusion}

In this study, we have demonstrated the potential of outer-selective TFC hollow fiber membranes for energy conversion via PRO process. The desirable morphology of Ultem ${ }^{\circledR}$ hollow fiber supports has been proposed and optimized by controlling the spinning parameters. A simple prewetting with alcohols has been applied for the support prior to the interfacial polymerization and its effect on polyamide layer morphology has been investigated in-depth. The following conclusions can be drawn based on this work:

(1) The support morphology with the mixed finger- and sponge-like structure is the most convenient one with efficiently strong mechanical properties and low internal 
concentration polarization for a high pressure tolerance (17 bar) and low water flux drop $(\sim 30 \%)$.

(2) By using alcohols with solubility parameters closer to that of the support and lower surface tension provides a more efficient pre-wetting so that m-phenylene diamine can be distributed more uniformly. Its transport is then less turbulent leading to a thin and smooth polyamide layer formation.

(3) The combination of moderate pressure tolerance and high initial flux, resulting from a strong support and a thin and smooth selective layer, provided a higher power density than previous reports in literature at similar operation conditions.

\section{Acknowledgement}

The authors thank the Water Desalination and Reuse Center and KAUST's Core Labs for their help on equipment and analysis. Thanks are due to Dr. Zhenyu Li for his kind help on PRO system, Mr. Burhannudin Sutisna at KAUST for his kind help on TEM imaging. Positron annihilation spectroscopy (PAS) was performed at National University of Singapore with help of Mr. Susilo Japip, Miss Zhang Yu and Mrs Hua Dan. The work was supported by King Abdullah University of Science and Technology (KAUST).

\section{References}

[1] U.S.E.I. Administration, Annual Energy Outlook 2014, Washington, U.S, 2014.

[2] B.E. Logan, M. Elimelech, Membrane-based processes for sustainable power generation using water, Nature, 488 (2012) 313-319. 
[3] J.W. Post, J. Veerman, H.V. Hamelers, G.J. Euverink, S.J. Metz, K. Nymeijer, C.J. Buisman, Salinity-gradient power: Evaluation of pressure-retarded osmosis and reverse electrodialysis, Journal of Membrane Science, 288 (2007) 218-230.

[4] T. Thorsen, T. Holt, The potential for power production from salinity gradients by pressure retarded osmosis, Journal of Membrane Science, 335 (2009) 103-110.

[5] R.J. Aaberg, Osmotic power: a new and powerful renewable energy source?, Refocus, 4 (2003) 48-50.

[6] K. Gerstandt, K.V. Peinemann, S.E. Skilhagen, T. Thorsen, T. Holt, Membrane processes in energy supply for an osmotic power plant, Desalination, 224 (2008) 64-70.

[7] S.E. Skilhagen, Osmotic power-a new, renewable energy source, Desalination and water treatment, 15 (2010) 271-278.

[8] R. Pattle, Production of electric power by mixing fresh and salt water in the hydroelectric pile, Nature, 174 (1954) 660.

[9] T.S. Chung, X. Li, R.C. Ong, Q. Ge, H. Wang, G. Han, Emerging forward osmosis (FO) technologies and challenges ahead for clean water and clean energy applications, Current Opinion in Chemical Engineering, 1 (2012) 246-257.

[10] J.T. Arena, B. McCloskey, B.D. Freeman, J.R. McCutcheon, Surface modification of thin film composite membrane support layers with polydopamine: enabling use of reverse osmosis membranes in pressure retarded osmosis, Journal of Membrane Science, 375 (2011) 55-62.

[11] N.N. Bui, J.R. McCutcheon, Hydrophilic nanofibers as new supports for thin film composite membranes for engineered osmosis, Environmental science \& technology, 47 (2013) 1761-1769. 
[12] S. Chou, R. Wang, A.G. Fane, Robust and High performance hollow fiber membranes for energy harvesting from salinity gradients by pressure retarded osmosis, Journal of Membrane Science, 448 (2013) 44-54.

[13] G. Han, P. Wang, T.S. Chung, Highly robust thin-film composite pressure retarded osmosis (PRO) hollow fiber membranes with high power densities for renewable salinity-gradient energy generation, Environmental science \& technology, 47 (2013) 8070-8077.

[14] G. Han, S. Zhang, X. Li, T.S. Chung, High performance thin film composite pressure retarded osmosis (PRO) membranes for renewable salinity-gradient energy generation, Journal of Membrane Science, 440 (2013) 108-121.

[15] X. Li, S. Zhang, F. Fu, T.S. Chung, Deformation and reinforcement of thin-film composite (TFC) polyamide-imide (PAI) membranes for osmotic power generation, Journal of Membrane Science, 434 (2013) 204-217.

[16] X. Song, Z. Liu, D.D. Sun, Energy recovery from concentrated seawater brine by thin-film nanofiber composite pressure retarded osmosis membranes with high power density, Energy \& Environmental Science, 6 (2013) 1199-1210.

[17] S. Zhang, T.S. Chung, Minimizing the instant and accumulative effects of salt permeability to sustain ultrahigh osmotic power density, Environmental science \& technology, 47 (2013) 10085-10092.

[18] S.E. Skilhagen, J.E. Dugstad, R.J. Aaberg, Osmotic power-power production based on the osmotic pressure difference between waters with varying salt gradients, Desalination, 220 (2008) 476-482. 
[19] F.J. Fu, S.P. Sun, S. Zhang, T.S. Chung, Pressure retarded osmosis dual-layer hollow fiber membranes developed by co-casting method and ammonium persulfate (APS) treatment, Journal of Membrane Science, 469 (2014) 488-498.

[20] S.P. Sun, T.S. Chung, Outer-selective pressure-retarded osmosis hollow fiber membranes from vacuum-assisted interfacial polymerization for osmotic power generation, Environmental science \& technology, 47 (2013) 13167-13174.

[21] A. Nagendran, D.R. Mohan, Cellulose acetate and polyetherimide blend ultrafiltration membranes: II. Effect of additive, Polymers for Advanced Technologies, 19 (2008) 24-35. [22] S. Zhang, F. Fu, T.S. Chung, Substrate modifications and alcohol treatment on thin film composite membranes for osmotic power, Chemical Engineering Science, 87 (2013) 40-50. [23] S. Nunes, K. Peinemann, K. Ohlrogge, A. Alpers, M. Keller, A. Pires, Membranes of poly (ether imide) and nanodispersed silica, Journal of Membrane Science, 157 (1999) 219-226.

[24] J. Zuo, Y. Wang, T.S. Chung, Novel organic-inorganic thin film composite membranes with separation performance surpassing ceramic membranes for isopropanol dehydration, Journal of Membrane Science, 433 (2013) 60-71.

[25] F.Y. Li, Y. Li, T.S. Chung, H. Chen, Y. Jean, S. Kawi, Development and positron annihilation spectroscopy (PAS) characterization of polyamide imide (PAI)-polyethersulfone (PES) based defect-free dual-layer hollow fiber membranes with an ultrathin dense-selective layer for gas separation, Journal of Membrane Science, 378 (2011) 541-550.

[26] W.S. Hung, M. De Guzman, S.H. Huang, K.R. Lee, Y. Jean, J.Y. Lai, Characterizing free volumes and layer structures in asymmetric thin-film polymeric membranes in the wet condition using the variable monoenergy slow positron beam, Macromolecules, 43 (2010) 6127-6134. 
[27] J. Zuo, Y. Wang, S.P. Sun, T.S. Chung, Molecular design of thin film composite (TFC) hollow fiber membranes for isopropanol dehydration via pervaporation, Journal of Membrane Science, 405 (2012) 123-133.

[28] K.Y. Wang, T. Matsuura, T.S. Chung, W.F. Guo, The effects of flow angle and shear rate within the spinneret on the separation performance of poly (ethersulfone)(PES) ultrafiltration hollow fiber membranes, Journal of membrane science, 240 (2004) 67-79.

[29] S. Kumbharkar, Y. Liu, K. Li, High performance polybenzimidazole based asymmetric hollow fibre membranes for $\mathrm{H}_{2} / \mathrm{CO}_{2}$ separation, Journal of Membrane Science, 375 (2011) 231240.

[30] J.J. Qin, T.S. Chung, Effects of orientation relaxation and bore fluid chemistry on morphology and performance of polyethersulfone hollow fibers for gas separation, Journal of membrane science, 229 (2004) 1-9.

[31] Z.L. Xu, T.S. Chung, K.C. Loh, B.C. Lim, Polymeric asymmetric membranes made from polyetherimide/polybenzimidazole/poly (ethylene glycol)(PEI/PBI/PEG) for oil-surfactantwater separation, Journal of membrane science, 158 (1999) 41-53.

[32] M. Aroon, A. Ismail, M. Montazer-Rahmati, T. Matsuura, Morphology and permeation properties of polysulfone membranes for gas separation: effects of non-solvent additives and cosolvent, Separation and Purification Technology, 72 (2010) 194-202.

[33] Y. Liu, G. Koops, H. Strathmann, Characterization of morphology controlled polyethersulfone hollow fiber membranes by the addition of polyethylene glycol to the dope and bore liquid solution, Journal of Membrane Science, 223 (2003) 187-199. 
[34] Z.W. Song, L.Y. Jiang, Optimization of morphology and perf ormance of PVDF hollow fiber for direct contact membrane distillation using experimental design, Chemical Engineering Science, 101 (2013) 130-143.

[35] S. Bonyadi, T.S. Chung, W.B. Krantz, Investigation of corrugation phenomenon in the inner contour of hollow fibers during the non-solvent induced phase-separation process, Journal of membrane science, 299 (2007) 200-210.

[36] W.L. Chou, M.C. Yang, Effect of take-up speed on physical properties and permeation performance of cellulose acetate hollow fibers, Journal of membrane science, 250 (2005) 259267.

[37] N. Peng, T.S. Chung, K.Y. Wang, Macrovoid evolution and critical factors to form macrovoid-free hollow fiber membranes, Journal of Membrane Science, 318 (2008) 363-372.

[38] Y. Tang, N. Li, A. Liu, S. Ding, C. Yi, H. Liu, Effect of spinning conditions on the structure and performance of hydrophobic PVDF hollow fiber membranes for membrane distillation, Desalination, 287 (2012) 326-339.

[39] A.K. Ghosh, E.M. Hoek, Impacts of support membrane structure and chemistry on polyamide-polysulfone interfacial composite membranes, Journal of Membrane Science, 336 (2009) 140-148.

[40] X. Li, K.Y. Wang, B. Helmer, T.-S. Chung, Thin-film composite membranes and formation mechanism of thin-film layers on hydrophilic cellulose acetate propionate substrates for forward osmosis processes, Industrial \& Engineering Chemistry Research, 51 (2012) 10039-10050.

[41] C. Kong, M. Kanezashi, T. Yamomoto, T. Shintani, T. Tsuru, Controlled synthesis of high performance polyamide membrane with thin dense layer for water desalination, Journal of Membrane Science, 362 (2010) 76-80. 
[42] W.C. Chao, S.H. Huang, Q. An, D.J. Liaw, Y.C. Huang, K.R. Lee, J.Y. Lai, Novel interfacially-polymerized polyamide thin-film composite membranes: studies on characterization, pervaporation, and positron annihilation spectroscopy, Polymer, 52 (2011) 2414-2421.

[43] T. Aminabhavi, V. Patil, M. Aralaguppi, H. Phayde, Density, viscosity, and refractive index of the binary mixtures of cyclohexane with hexane, heptane, octane, nonane, and decane at (298.15, 303.15, and 308.15) K, Journal of Chemical \& Engineering Data, 41 (1996) 521-525.

[44] A.F. Barton, Solubility parameters, Chemical Reviews, 75 (1975) 731-753.

[45] D.R. Bessire, E.L. Quitevis, Effect of temperature and viscosity on rotational diffusion of merocyanine 540 in polar solvents, The Journal of Physical Chemistry, 98 (1994) 13083-13092. [46] J. Bicerano, Prediction of polymer properties Marcel Dekker, New York 1993.

[47] J.V. Gasa, R. Weiss, M.T. Shaw, Influence of blend miscibility on the proton conductivity and methanol permeability of polymer electrolyte blends, Journal of Polymer Science Part B: Polymer Physics, 44 (2006) 2253-2266.

[48] R.L. Schmidt, J.C. Randall, H.L. Clever, The surface tension and density of binary hydrocarbon mixtures: benzene-n-hexane and benzene-n-dodecane, The Journal of Physical Chemistry, 70 (1966) 3912-3916.

[49] N. Sivaraman, R. Dhamodaran, I. Kaliappan, T. Srinivasan, P.V. Rao, C. Mathews, Solubility of C60 in organic solvents, The Journal of Organic Chemistry, 57 (1992) 6077-6079.

[50] A. Valtz, M. Teodorescu, I. Wichterle, D. Richon, Liquid densities and excess molar volumes for water+ diethylene glycolamine, and water, methanol, ethanol, 1-propanol+ triethylene glycol binary systems at atmospheric pressure and temperatures in the range of 283.15-363.15 K, Fluid phase equilibria, 215 (2004) 129-142. 
[51] R.C. Weast, M.J. Astle, CRC Handbook of Chemistry and Physics, 63rd ed., CRC Press, Florida, 1982-1983.

[52] A. W. Adamson, A. P. Gast, Physical Chemistry of Surfaces, $6^{\text {th }}$ ed., John Wiley \& Sons, New York, 1997.

[53] G. Vazquez, E. Alvarez, J. M. Navaza, Surface tension of alcohol and water from 20 to 50C, J. Chem. Eng. Data, 40 (1995) 611-614. 


\title{
List of abbreviations and nomenclatures
}

\author{
Abbreviations \\ DEG : diethylene glycol \\ FESEM : scanning electron microscope \\ FO : forward osmosis \\ NMP : N-methyl-pyrrolidone \\ MWCO : molecular weight cut-off \\ PAN : polyacrylonitrile \\ PAS : positron annihilation spectroscopy \\ PBI : polybenzimidazole \\ POSS : polyhedral oligomeric silsesquioxane \\ PVP : polyvinylpyrrolidone \\ PWP : pure water permeance \\ PRO : pressure-retarded osmosis \\ RO : reverse osmosis \\ TEM : transmission electron microscope \\ TFC : thin film composite
}

\section{Nomenclatures}
$\mathrm{A}_{\mathrm{m}} \quad$ : effective membrane area $\left(\mathrm{m}^{2}\right)$
$\mathrm{c}_{\mathrm{p}} \quad:$ solute concentration in the permeate $(\mathrm{mg} / \mathrm{L})$
$\mathrm{c}_{\mathrm{f}} \quad$ : solute concentration in the feed $(\mathrm{mg} / \mathrm{L})$ 


\begin{tabular}{|c|c|}
\hline $\mathrm{c}_{\mathrm{o}}$ & : salt concentration the initial feed (mg/L) \\
\hline$c_{t}$ & : salt concentration of the final feed $(\mathrm{mg} / \mathrm{L})$ \\
\hline $\mathrm{E}$ & : incident positron energy $(\mathrm{keV})$ \\
\hline $\mathrm{J}_{\mathrm{s}}$ & : salt reverse flux $\left(\mathrm{gm}^{-2} \mathrm{~h}^{-1}\right)$ \\
\hline $\mathrm{J}_{\mathrm{w}}$ & : water permeation flux $\left(\mathrm{Lm}^{-2} \mathrm{~h}^{-1}\right)$ \\
\hline Q & : water permeation volumetric flow rate $(\mathrm{L} / \mathrm{h})$ \\
\hline $\mathbf{R}_{\mathrm{T}}$ & : solute rejection $(\%)$ \\
\hline $\mathrm{t}$ & : time $(s)$ \\
\hline $\mathrm{v}_{\mathrm{o}}$ & : volume of the initial feed (L) \\
\hline $\mathrm{v}_{\mathrm{t}}$ & : volume of the final feed (L) \\
\hline $\mathrm{W}$ & : power density $\left(\mathrm{W} / \mathrm{m}^{2}\right)$ \\
\hline $\mathrm{W}_{\mathrm{s}}$ & : weight of swollen strips (mg) \\
\hline $\mathrm{W}_{\mathrm{o}}$ & : weight of dry strips (mg) \\
\hline $\mathrm{Z}$ & : mean implantation depth (nm) \\
\hline$\mu_{\mathrm{p}}$ & : mean pore size $(\mathrm{nm})$ \\
\hline$\rho$ & : density of the polymer material $\left(\mathrm{g} / \mathrm{cm}^{3}\right)$ \\
\hline$\sigma_{\mathrm{p}}$ & : geometric standard deviation \\
\hline$\Delta \mathrm{P}$ & : transmembrane pressure drop (bar) \\
\hline$\Delta \pi$ & : osmotic pressure difference (bar) \\
\hline
\end{tabular}




\section{List of Tables}

Table 1. PRO performance of outer-selective hollow fiber membranes in literature

Table 2. Spinning conditions of Ultem ${ }^{\circledR}$ hollow fiber supports

Table 3. Outer diameter, mean pore size, standard deviation, MWCO, collapse pressure and pure water permeance (PWP) of Ultem ${ }^{\circledR}$ hollow fiber supports

Table 4. Physicochemical properties of Ultem ${ }^{\circledR}$, water, methanol, ethanol, n-propanol and nhexane 


\section{List of Figures}

Figure 1. Morphology of the hollow fiber supports used for fabricating the outer-selective PRO membranes: (a) cross-section, (b) inner surface, and (c) outer surface

Figure 2. Detailed morphology of hollow fiber supports for preparing the outer-selective PRO membranes

Figure 3. (a) Outer surface and (b) outer edge morphology of outer-selective TFC hollow fiber membranes prepared from different supports (FESEM images; insets are TEM images)

Figure 4. S parameter as a function of position incident energy of TFC hollow fiber membranes prepared from different supports

Figure 5. (a) Water permeance (A) and salt permeance (B) of outer-selective TFC hollow fiber membranes, and (b) Water flux and salt reverse flux of outer-selective TFC hollow fiber membranes

Figure 6. PRO performance of outer-selective TFC hollow fiber membranes: (a) water flux and (b) power density as a function of pressure

Figure 7. (a) Outer surface and (b) outer-edge morphology of outer-selective TFC hollow fiber membranes prepared from the HF-4 supports pre-wetted with water, methanol, ethanol and n-propanol (FESEM images; insets are TEM images)

Figure 8. $\mathrm{S}$ parameter as a function of position incident energy of TFC hollow fiber membranes prepared from the HF-4 supports pre-wetted with water and alcohols

Figure 9. (a) Degree of sorption of the HF-4 fiber analogous flat-sheet supports in different solvents at room temperature; (b) Water permeance (A) and salt permeance (B); and 
(c) Water flux and salt reverse flux of outer-selective TFC hollow fiber membranes prepared from the HF-4 supports pretreated with different solvents

Figure 10. PRO performance of the outer-selective TFC hollow fiber membranes prepared from n-propanol pre-wetted HF-4 support: water flux and power density as a function of pressure 